\title{
Chapter 6 \\ Determinants of Contract Renewals in University-Industry Contract Research: Going my Way, or Good Sam?
}

\author{
Tohru Yoshioka-Kobayashi and Makiko Takahashi
}

\begin{abstract}
Long-term university-industry contract research benefits both universities and the industry, as it can potentially reduce transaction costs and improve the quality of such collaborations. Nevertheless, trade-offs between the advantages and disadvantages of long-term contracts motivate firms to enter stage-gate contracts (i.e., a shorter contract period with an expectation of renewal or extension) to avoid uncertainty over collaboration's performance. This study addresses two less understood questions in the contract renewal or extension decision: longitudinal changes in the strength of the commitment to the collaboration and the determinants of renewals. We empirically test these issues with 1562 research contracts from a leading Japanese university, and we match this database to a questionnaire survey results obtained from its industrial counterparts. Our empirical test identified an inverse-U-shaped effect on the degree of commitment in the time elapsed since the first research contract. We also found that firms are more likely to renew or extend a contract when they perceive technological knowledge learning or co-publish an academic paper. Our findings suggest that university-industry contract research focused on academic research-related activities (or academic researcher's "going my way") is likely to establish long-term collaborations.
\end{abstract}

Keywords Contract research · Contract renewal - University-industry collaboration

T. Yoshioka-Kobayashi $(\bowtie)$

Institute of Innovation Research, Hitotsubashi University, Kunitachi, Tokyo, Japan

e-mail: t-koba@iir.hit-u.ac.jp

M. Takahashi

Graduate School of Innovation Management, Kanazawa Institute of Technology, Nonoichi,

Ishikawa, Japan

J. M. Azagra-Caro et al. (eds.), University-Industry Knowledge Interactions, International Studies in Entrepreneurship 52,

https://doi.org/10.1007/978-3-030-84669-5_6 


\subsection{Introduction}

Managing university-industry linkages is an essential topic in national and regional science and technology policy as well as in organizational management and open innovation contexts. A multitude of research studies address the determinants of successful collaboration, such as the alignment of motivations for interactions (Morandi, 2013), the formation of mutual personal trust (Santoro \& Saparito, 2006; Plewa \& Quester, 2006), and the management of pervasive uncertainty (Morandi, 2013; Petruzzelli, 2011). Nonetheless, no universally applicable determinants have emerged, because of the diversity of interaction modes.

Following a framework developed by D'Este et al. (2019), which characterizes a university-industry interaction, we can systematically identify and understand multiple determinants. The framework differentiates relational arrangements from transactional arrangements - the former referring to a personally based relationship, with frequent communication, and the latter corresponding to relationships that do not include frequent personal interactions, such as patent licensing. Relational arrangements are a major aspect of university-industry collaborations (Bodas Freitas et al., 2013). Interactions in this relational arrangement inexorably require mutual trust between individuals from both the industry and university levels (Bruneel et al., 2010; Bstieler et al., 2015; Santoro \& Saparito, 2006). Without trust, both parties are not likely to openly share information (Plewa et al., 2013).

A key factor of trust formation is long-term linkage (Bruneel et al., 2010; Garcia et al., 2020). Shared vocabularies and reduced communicational barriers stimulate necessary information sharing and such reciprocal communication enhances the formation of trust (Bstieler et al., 2015), which subsequently increases the frequency and efficiency of personal communication. Furthermore, a long-term linkage reduces the transaction costs associated with interorganizational communication (Weckowska, 2015), allowing both parties to establish flexible modification in the collaborative arrangement as needed. Accordingly, such longitudinal linkages not only demonstrate superior academic productivity in contrast to short-term collaborative research and development (R\&D) activities (Bstieler et al., 2015; Garcia et al., 2020) but also have the potential to elicit innovation based on radical scientific discoveries (Motoyama, 2014). Consequently, in many cases, both academia and industry prefer to develop long and stable collaborative arrangements (Ankrah et al., 2013).

Long-term collaborative arrangements are often associated with multiple reciprocal outcomes. One of the main outcomes of longitudinal joint $R \& D$ projects is that both parties gain additional benefits beyond R\&D results. Academic scholars benefit from the learning opportunities available through engaging in industry research and receiving feedback from industry collaborators (Perkmann \& Walsh, 2007; D'Este \& Perkmann, 2011; Landry et al., 2010). This can result in the publication of academic papers that are co-authored with industry colleagues (Tijssen et al., 2009; Yegros-Yegros et al., 2016). Collaborating industry firms foster the development of technological capabilities (Bishop et al., 2011; Ankrah et al., 2013) and 
social capital with academia (Hagedoorn et al., 2000), while sustaining continuous access to the latest scientific knowledge. Most of these benefits emerge from frequent, trust-based communication between industry and academia (Petruzzelli, 2011; D’Este et al., 2019).

Nevertheless, formal contracts are associated with the necessity of management. The establishment of a long-term research contract is equivalent to a request for both parties to tolerate uncertainties regarding the potential outcomes to be obtained and the indeterminate performance-outcome effectiveness of a linkage (e.g., Perkmann et al., 2011). As firms generally endeavour to prevent uncertain investment, contractual arrangements that reduce risks from uncertainties are often sought. A stage-gate contract is one such solution. This contractual arrangement establishes phased-reviews and subsequent contract renewals (i.e., new contract arrangements between the same parties to continue joint research) or extensions (i.e., an extension of contract terms and/or increased budgets or monetary contributions) to balance the reduction of uncertainty and the continuation of long-term interactions. Many firms employ such arrangements in R\&D outsourcing (Wang et al., 2018), and some scholars have also recommended this approach in university-industry collaborations (Starbuck, 2001; Jelinek \& Markham, 2007). Although no data currently exist supporting the efficacy of the actual use of stage-gate contracts in universityindustry collaborations, Garcia et al. (2020) provide indirect evidence. Among collaborative research between industry and Spanish academic researchers, only $38 \%$ establish contracts lasting for more than 1 year. This proportion seems to be low, considering the nature of contract research, which often involves research with open-ended goals. We can assume that the wide use of stage-gate contracts simplifies the termination of underperforming university-industry interactions when necessary.

Even when establishing a long-term relationship, using stage-gate contracts as an effective approach, both industry liaison officers and academic researchers engaged in the interaction face two puzzles. First, at the beginning of the interaction, they cannot estimate how long the relationship will be maintained, as it is unreasonable to expect a long-lasting commitment to interaction. We can assume that firms increase their commitment to a renewed collaborative relationship in the first couple of years and potentially decrease after that. If they can determine general trends in the strength of commitment, both industry and research institutions will be better able to predict how long a relationship will be maintained. Second, it is difficult to estimate the probability of a contract renewal in the beginning of a collaboration, as the determinants of continuity remain even less understood. Although Perkmann et al. (2011) clarify multiple performance measurements for firms, we do not fully know how these measurements are actually considered. R\&D managers and policymakers occasionally emphasize the assimilation of academic researchers in the industry context. To maintain long-term collaboration, which actions should an academic researcher take: assimilation into the industry, behaviour as a helpful partner ("a good Sam"), or maintenance of their academic principles ("going my way")? 
Long-term university-industry relationships are often desirable; however, little is known about how these long-term relationships form or evolve. We examine these processes by studying both contract renewals and extensions. To our knowledge, this has never been done previously in such a systematic manner. Using research contract data from an anonymous Japanese university, covering contract research entered into from 2005 to 2014 (approximately 500 contracts per year) and ultimately yielding 1562 research contracts, this paper examines two critical issues of universityindustry contract research: time-dependent changes in the strength of commitment and the determinants of continuity. The main contributions are empirical evidence of contract renewals and related managerial insights.

The remainder of this paper is organized to present a literature review and attending hypotheses in Sect. 6.2, followed by an overview of the methodology employed for the study in Sect. 6.3. Section 6.4 describes the detailed results of the study, and Sects. 6.5 and 6.6 offer a discussion of the results and research conclusions.

\subsection{Literature Review and Hypotheses}

\subsubsection{Strength of Interaction Commitment and Contract Length}

Two perspectives encompass the trade-offs of long-term interaction. From a resource development perspective, the time duration of interactions is linearly beneficial. Long-term interaction is associated with greater communication and mutual trust (Bruneel et al., 2010; Garcia et al., 2019). Heightened trust increases the expectations for collaborative research outputs, and strengthens counterparties' commitment to the focal interaction, characterized by the willingness to engage in a two-way collaborative process that complies with the goals of both partners (Frasquet et al., 2012; Lauvas \& Steinmo, 2019). In contrast, from a resource exchange perspective, different consequences are expected of the duration. Time in collaboration develops shared vison, norms, and language (Al-Tabbaa \& Ankrah, 2016; Dingler \& Enkel, 2016), which stimulate the efficient and effective exchange of knowledge (GalanMuros \& Plewa, 2016). However, over time, these shared normative and behavioural elements tend to construct rigid routines to facilitate now-familiar knowledge patterns of exchange and act to filter out novel ideas (Zheng \& Yang, 2015). Long-term linkages run the risk of drifting into exploitation at the expense of exploration (Koza \& Lewin, 1998). This is an undesirable consequence for firms, as they often use university-industry linkages as a measure for exploration (Perkmann et al., 2011). In other words, longitudinal collaborations are often effective for an exchange of specific knowledge, but are not considered favourable to the advancement of continuous learning from counterparts. The resource exchange perspective implies a nonlinear effect of time. Combining different consequences from two perspectives, 
we can assume that the length of collaboration exerts an inverse-U-shaped effect on commitment.

This assumption is supported by several points of collateral evidence. In a simulation study, the value of $R \& D$ collaboration hits a peak of around 2-4 years because of an accompanying saturation of learning (Katz \& Allen, 1982). Im and Rai's (2008) university-industry collaboration study also demonstrates that some firms do not prefer lengthy interactions. Another study indicates that lengthy university-industry interactions actually decrease academic productivity (BanalEstañol et al., 2015). These studies are consistent with the implied consequences of our argument above, leading to the following hypothesis:

Hypothesis 1 Renewed or extended contracts are associated with greater commitment, which is saturated by the time length of past collaborations.

\subsubsection{The Determinants of Contract Renewals or Extensions of Research Contracts}

The above hypothesis only relates to renewed or extended contracts. Before a renewal or extension, a firm makes a "Continue or Not" decision. The essence of a stage-gate contract, (i.e., performance based-evaluation of the collaboration), indicates how an intermediate outcome is important for such a decision. In evaluating a tentative outcome, a firm can estimate performance-outcome effectiveness. This approach can be applied to every type of personal-based university-industry research contract other than staged contracts. Scholarly works on both universityindustry contract research and research consortia among firms imply that such a tentative outcome directly affects the perceptions of the performance-outcome effectiveness of a collaboration or constitutes an essential part of experiential learning (Ebers \& Maurer, 2016).

Experiential learning is important in collaboration, and is accompanied by specific uncertainties. Firms often interpret projects' performance based on the actual experience of the project in reference to further resource allocation decisions (Schwab \& Miner, 2008). Ebers and Maurer (2016) found that satisfaction with the outcomes of a previous collaboration is an excellent sign of experiential learning on performance-outcome effectiveness and subsequently increases the likelihood of the collaboration continuing. Although their study does not include research collaborations, its theoretical contribution can be applied in the context of universityindustry R\&D collaboration. As argued above, firms often have great concern with effectiveness. Satisfaction with outcomes directly indicates the dissolution of this concern. Hence, it will increase the probability of a continuity decision. Hypothesis 2 follows this line of thought:

Hypothesis 2 Satisfaction with the outcome obtained is positively related to the renewal or extension of a collaboration. 
Nevertheless, from a resource exchange perspective, we expect that firms are less likely to repeat a collaboration when faced with doubt regarding a future outcome. Considering the heterogeneity of outcomes, we suspect that some types of outcomes may result in the suspension of additional collaboration because of their unrepeatability or future constraints.

Before debating the different outcome influences, we need to investigate the established typology of contract research outcomes. Following the work of Perkmann et al. (2011), from the industry perspective, outcomes can be classified into outputs and impact. Outputs include new technologies, new scientific knowledge, and skilled and trained staff. Impact corresponds to innovative ideas for products or services, new solution concepts (i.e., architectures or designs representing solutions to particular problems), improvements of ongoing R\&D programs, and human capital development (i.e., the recruitment of staff from the university, and building network capital). Outputs are a direct achievement of collaboration, but do not always generate any direct business impact. Impact, conversely, potentially contributes to the business directly.

In terms of outputs, all of them support the technological capability development of firms. As more prolonged collaborations develop absorptive capacity, which stimulates knowledge exchange and subsequent mutual learning (Schildt et al., 2012), once firms perceive some extent of technological capability development through focal contract research, renewals become a reasonable option. New technologies, new scientific knowledge, and staff skills and training are regarded as positive intermediate outputs for a continuation.

In this regard, Perkmann et al. (2011) emphasize explicit outputs, such as patents or publications, as their measurements. We differentiate explicit and implicit outputs, in consideration of the inherent opportunistic behaviour of firms. When firms recognize improved capabilities, they may engage their bargaining power to maintain such interactions informally (Hamel, 1991). Particularly, clear evidence of capability development may negatively affect the maintenance of formal interactions, as firms can internally improve and build on the knowledge acquired (Olk \& Young, 1997). In the university-industry collaborative research context, co-authored papers, patent filings, or valuable data acquisitions are explicit signals of technological capability development. This may result in a decreased probability of continuation.

Meanwhile, staff skills and training are related to a different constraint that derives from rational organizational decisions. A human resource management study asserts a necessity of justification for scarce resource allocation (Swanson, 2001). When firms aim at training incumbent R\&D personnel, they face a challenge to continue the allocation of previously developed human resources to the contract research, as R\&D personnel are often scarce human resources for a firm. Alternatively, allocated personnel can be replaced on a collaborative project, but such a replacement is inconsistent with the development and positive outcomes of personalbased relationship. Thus, we can assume that staff skill development is negatively related to contract continuation. 
From the same perspective, we assume that similar trade-offs emerge in some types of impact, including new ideas for products or services, new concepts for solutions, or improvements to ongoing R\&D programs seem to face similar tradeoffs. The internal justification for further formal resource allocation to the collaboration may be diminished for firms because they have already achieved impact and academic researchers are generally not suitable partners for the downstream product or service development process (e.g., Vohora et al., 2004).

Network capital development is an aspect that is distinctive from others. Particularly under the increasing recognition of the development of social networks as one of the drivers of innovation when firms collaborate with academic researchers (Steinmo \& Rasmussen, 2018), firms expect future knowledge acquisitions and human resource development through the social network developed with academic researchers. Considering the personal nature of university-industry collaborations, which are sustained for a long period (De Fuentes \& Dutrénit, 2012), maintaining a formal relationship is an effective way to strengthen personal connections.

The arguments above do not lead to clear hypotheses regarding the influence of specific kinds of outcomes. Nevertheless, we can at least expect that each type of outcome has a potentially heterogeneous influence on decisions concerning renewal or extension. Some outcomes will positively increase the probability of renewal or extension, while others will not. Hypothesis 3 endeavours to accurately capture this question.

Hypothesis 3 Types of outcomes obtained are related to the renewal or extension of the collaboration.

\subsection{Methodology}

\subsubsection{Dataset}

Our examination used a research contract database from an anonymous Japanese university, a leading research university that conducts approximately 500 research projects in collaboration with the industry sector annually. The database covers the university's contract research entered into from 2005 to 2014. The data for each contract include the research budget, names of the principal investigators (PIs) and counterpart firms, contract start and end dates, and extended contract end date (if any). An advantage of these Japanese data is its volume. Multiple incentives since the early 2000s have compelled academic researchers to sign formal contracts, rather than collaborating through traditional informal channels (Kameo, 2015).

We identified contract renewals by aggregating contracts that shared the same PI and counterpart-firm pairs, calling a set of contracts a project. This method simplifies the university-industry connection as the relationship between an individual academic researcher and a specific firm. We distinguish contract renewals from contract extensions (see Fig. 6.1), as such research budget allocations are fundamentally 


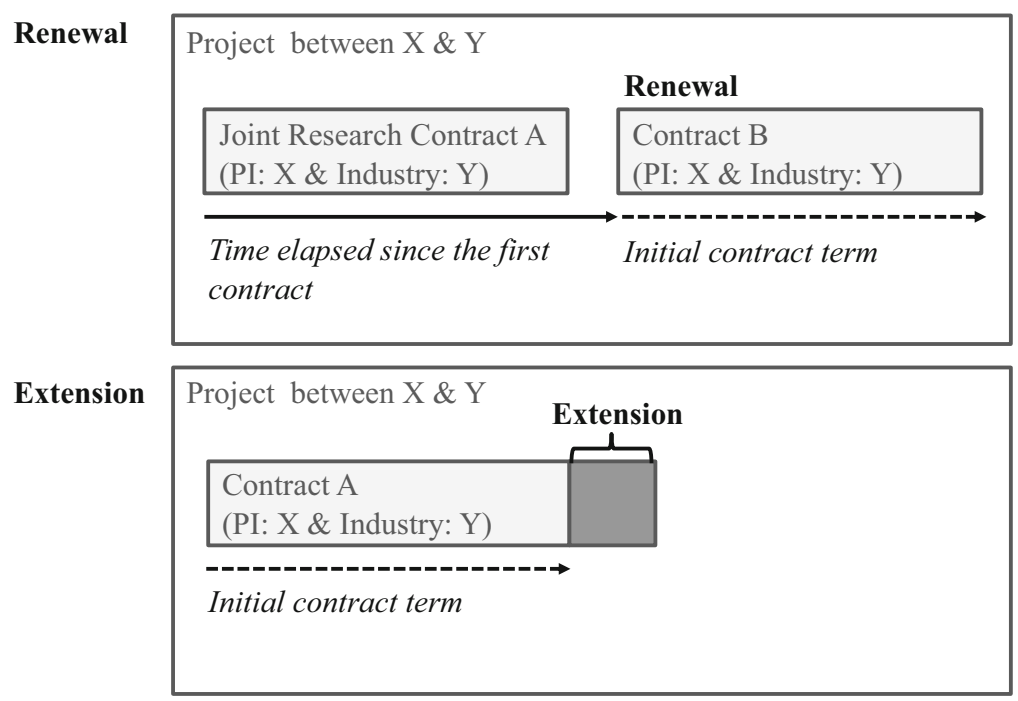

Fig. 6.1 Definitions of contract renewals and extensions

Table 6.1 Descriptive statistics of contract research in our observation (2005-2014)

\begin{tabular}{l|l|l|l|l}
\hline Term & \multicolumn{2}{|l|}{ Individual contracts } & \multicolumn{2}{l}{ Projects: Aggregated by PI-firm pairs } \\
\hline 1 year and less & 3894 & $(75.7 \%)$ & 1513 & $(53.4 \%)$ \\
\hline 2 years & 634 & $(12.3 \%)$ & 710 & $(25.0 \%)$ \\
\hline 3-4 years & 426 & $(8.3 \%)$ & 426 & $(15.0 \%)$ \\
\hline 5-7 years & 157 & $(3.1 \%)$ & 155 & $(5.5 \%)$ \\
\hline 8-years & 35 & $(0.7 \%)$ & 31 & $(1.1 \%)$ \\
\hline Average term & 1.32 & Years & 1.96 & Years \\
\hline
\end{tabular}

different. Considering the freedom of contracts, as previously argued, some extensions are assumed to be substantially equal to a contract renewal. However, in our dataset, only $4 \%$ of extended research contracts received significantly large amounts of additional budget (more than $50 \%$ of the initial budget). Thus, we maintain the formal distinction between renewals and extensions in our tests.

Table 6.1 displays the descriptive statistics of the contract terms in our dataset. When we aggregate contracts and calculate the duration between the first contract start date and the final contract end date, we find that $46.6 \%$ of contract research projects were maintained for more than 1 year. The average contract term of a project reveals a 1.96-year average, $49 \%$ longer than the average term of an individual contract.

As the projects in our operationalization have a truncation bias, our examination limited data from 2008 to 2011, to ensure sufficient time intervals. Furthermore, PIs' moves to other institutions generate another truncation bias, and thus, we excluded all data that included principal researchers who transferred to other institutions before 2013. Finally, we omitted contracts led by non-teaching staff, such as 
Table 6.2 Comparisons of our two sets of samples

\begin{tabular}{l|l|l}
\hline & $\begin{array}{l}\text { Full sample } \\
(2008-2011)\end{array}$ & $\begin{array}{l}\text { Subset sample } \\
(2008,2011)\end{array}$ \\
\hline Number of contracts & 1562 & 137 \\
\hline Average contract terms (years) & 1.31 & 1.35 \\
\hline Average budgets (million JPY) & 2.98 & 2.92 \\
\hline Renewed or extended & $61 \%$ & $66 \%$ \\
\hline Departments of PIs & & \\
\hline Medical/pharmaceutical & $15 \%$ & $13 \%$ \\
\hline Biology/other medical & $4 \%$ & $7 \%$ \\
\hline Science/engineering & $79 \%$ & $77 \%$ \\
\hline Humanities/social sciences & $2 \%$ & $2 \%$ \\
\hline
\end{tabular}

technicians, medical doctors, and visiting professors, as some of these projects are too heterogeneous. The final number of observations in our sample is 1562 research contracts.

We also linked questionnaire survey results with the database, as the questionnaire covers collaborations' initial purposes and tentative or final outcomes. The technology licensing office conducts this survey every 3 years for all joint research contracts entered into in that year, with a response rate of approximately $40 \%$. Thus, our subset sample is reduced to 137 research contracts. The contracts in this sample have longer terms, lower budgets, and a higher probability of renewal or extension (Table 6.2). Our unit of analysis is a contract. Extended contracts are not counted independently from base contracts.

\subsubsection{Models and Variables}

\subsubsection{Models and Variables for Analysis 1}

We examine our hypotheses by constructing two analysis models. Analysis 1 investigates H1, using our full samples. Table 6.3 displays the descriptive statistics.

We considered that the strength of interaction commitments can be measured by budget allocations. Budgets are of critical importance for university researchers (Lee, 2000) and represent a partner firm's perception of the expected value of a collaboration. Thus, our dependent variable in Analysis 1 is the size of the industryfunded research budgets for each research contract at the time of the contract ending. We calculated quarterly research budgets by considering the industry sector's accounting practices and the fact that the majority of contacts expired within 1 year. We took the natural logarithm of research budgets per quarter plus one and conducted an ordinary least-squares regression to estimate the dependent variable.

Our main independent variable is the time elapsed from the first contract to the date of the focal contract. This variable is 0 if the contract is the first contract between a PI and a firm; otherwise, it is the length of time elapsed from the start date of the 
Table 6.3 Descriptive statistics for Analysis 1

\begin{tabular}{l|l|l|l|l|l}
\hline & & Mean & Std. Dev. & Min & Max \\
\hline 1 & Ln (quarterly research budgets +1) & 12.10 & 3.24 & 0 & 16.18 \\
\hline 2 & Time elapsed from the first contract (years) & 1.14 & 1.43 & 0 & 6 \\
\hline 3 & Extension dummy & 0.15 & 0.36 & 0 & 1 \\
\hline 4 & Initial contract periods (quarters) & 5.25 & 5.48 & 1 & 58 \\
\hline 5 & On-site industry researchers & 0.17 & 0.48 & 0 & 5 \\
\hline 6 & PIs' U-I linkages & 2.87 & 3.34 & 0 & 21 \\
\hline 7 & Professor & 0.76 & 0.43 & 0 & 1 \\
\hline 8 & Associate Professor & 0.18 & 0.38 & 0 & 1 \\
\hline 9 & Lecturer/Assistant Professor & 0.07 & 0.25 & 0 & 1 \\
\hline 10 & Medical/Pharmaceutical & 0.15 & 0.36 & 0 & 1 \\
\hline 11 & Biology/Other Medical & 0.04 & 0.20 & 0 & 1 \\
\hline 12 & Science/Engineering & 0.79 & 0.41 & 0 & 1 \\
\hline 13 & Humanities/Social Sciences & 0.02 & 0.13 & 0 & 1 \\
\hline
\end{tabular}

\begin{tabular}{|c|c|c|c|}
\hline \multicolumn{4}{|c|}{ Project between X \& Y } \\
\hline First contract & Renewal & \multicolumn{2}{|c|}{ Renewal \& Extension } \\
\hline \begin{tabular}{|l|} 
Contract A \\
$(\mathrm{X} \& \mathrm{Y})$
\end{tabular} & $\begin{array}{l}\text { Contract B } \\
(\mathrm{X} \& \mathrm{Y})\end{array}$ & \begin{tabular}{|l} 
Contract C \\
$(\mathrm{X} \& \mathrm{Y})$
\end{tabular} & $\mathrm{C}^{\prime}$ \\
\hline \multicolumn{4}{|c|}{$\begin{array}{l}X \\
\text { Time elapsed from the first } \\
\text { contract (for Contract } A)=0\end{array}$} \\
\hline \multicolumn{4}{|c|}{$\begin{array}{ll}\text { Time elapsed from the first } & \text { Initial contract term } \\
\text { contract (for Contract } B) & \text { (for Contract B) }\end{array}$} \\
\hline $\begin{array}{l}\text { Time elapsed } f r \\
\text { contract (for } C\end{array}$ & $\begin{array}{l}\text { first } \\
\text { C) }\end{array}$ & $\begin{array}{l}\text { Initial cont } \\
\text { (for Contra }\end{array}$ & \\
\hline
\end{tabular}

Fig. 6.2 Examples of time elapsed from the first contract

first contract to the start date of the focal contract (see Fig. 6.2). As argued in H1, we inserted squared terms for these two time-related variables to test the curvilinear effects.

As a control variable, we added the initial contract periods noted in the quarters. This variable is used to control a potential discount of the research budget accompanying a long-term contract since firms may consider risk premium coming from performance-outcome effectiveness uncertainty. Additionally, as a factor in the commitment, we inserted the number of PIs in other university-industry collaborations which indicates the number of firms that conducted contract research with the PI in the contract's initial year. It is reasonable to assume that the greater the number of firms that connect with a particular PI, the less the investigator is able to commit to a single project. Conversely, this variable also represents a researcher's popularity. As such, this may have both a negative and a positive influence on commitment. We 
also used the number of researchers who belong to the counterparty, and who are registered as full- or part-time research fellows at the PI's office or laboratory. This variable potentially captures as a strength of the commitment. Finally, we added the PIs' positions and their school/department categories.

\subsubsection{Models and Variables for Analysis 2}

To test Hypotheses H2-H3, Analysis 2 examines the probability of renewal or extension using our subset samples. Table 6.4 displays the descriptive statistics.

A dependent variable of Analysis 2 is the renewal or extension dummy, which assumes a value of one if the joint research contract was renewed or extended substantially and zero otherwise. In our data, $66 \%$ of contracts experienced a renewal or extension. We chose to conduct a logit regression analysis to estimate the probability of a renewal or an extension.

The independent variables are outcome-related factors. For the test of H2, we employed the overall score in satisfaction with outcomes (satisfaction with outcomes) using a five-point Likert scale, in which five indicates "high satisfaction with outcomes." For the test of $\mathrm{H} 3$, we prepared eight variables that represent the values

Table 6.4 Descriptive statistics for Analysis 2

\begin{tabular}{l|l|l|l|l|l}
\hline & & Mean & Std. Dev. & Min & Max \\
\hline 1 & Subsequent renewal or extension dummy & 0.66 & 0.48 & 0 & 1 \\
\hline 2 & Satisfaction with outcomes (5-scale) & 4.18 & 0.71 & 2 & 5 \\
\hline 3 & Technological knowledge acquisition & 0.51 & 0.43 & 0 & 1 \\
\hline 4 & Patent application & 0.10 & 0.23 & 0 & 1 \\
\hline 5 & Academic paper publication & 0.22 & 0.32 & 0 & 1 \\
\hline 6 & Valuable data acquisition & 0.35 & 0.42 & 0 & 1 \\
\hline 8 & Staff skill development & 0.14 & 0.27 & 0 & 1 \\
\hline 9 & Creating social ties with faculty & 0.15 & 0.20 & 0 & 1 \\
\hline 10 & New project establishment & 0.06 & 0.24 & 0 & 1 \\
\hline 11 & Time elapsed from the first contract (years) & 0.17 & 0.30 & 0 & 1 \\
\hline 12 & On-site industry researchers & 0.16 & 1.44 & 0 & 6 \\
\hline 13 & Ln(research budgets +1) & 12.58 & 0.65 & 0 & 5 \\
\hline 14 & Initial contract periods (quarters) & 5.40 & 4.99 & 1 & 24 \\
\hline 15 & PIs' U-I linkage & 2.62 & 2.33 & 0 & 14 \\
\hline 16 & Professor & 0.78 & 0.42 & 0 & 1 \\
\hline 17 & Associate Professor & 0.17 & 0.38 & 0 & 1 \\
\hline 18 & Lecturer/Assistant Professor & 0.05 & 0.22 & 0 & 1 \\
\hline 19 & Medical/Pharmaceutical & 0.13 & 0.34 & 0 & 1 \\
\hline 20 & Biology/Other Medical & 0.07 & 0.26 & 0 & 1 \\
\hline 21 & Science/Engineering & 0.77 & 0.42 & 0 & 1 \\
\hline 22 & Humanities/Social Sciences & 0.02 & 0.15 & 0 & 1 \\
\hline & & & & 0 & 16.03 \\
\hline
\end{tabular}


obtained from individual types of outcomes. First, we asked the project's counterparty for the outcomes obtained-including both favourable and unfavourable ones - in each category, which included technological knowledge acquisition, patent application, academic paper publication, valuable data acquisition, staff skill development, creating social ties with faculty, new project establishment, contribution to internal R\&D and new product development (NPD) activities. Each category was sequentially ranked between 1 and 10 (where 1 represents "high value"), following the subjective value for counterparties if any outcomes were obtained. We adopted reciprocal numbers of these ranks as our independent variables; for example, if an outcome's value is ranked 3rd, a corresponding outcome variable takes $0.33(=1 / 3)$.

We must note that all these variables require an intermediate outcome. However, 16 respondents chose not to answer their outcomes and two did not disclose their score on satisfaction with outcomes. To check the sampling bias, we run the regression using a dummy variable, which takes one if the respondent answered their outcomes. The result ${ }^{1}$ does not indicate a significant sampling bias.

Multiple control variables are adopted to reduce an unobserved variable bias. The existence of previous formal collaborations formulates mutual trust (Bruneel et al., 2010) and reduces transaction costs (Weckowska, 2015); thus, it may stimulate a renewal or an extension. Our analysis used the time elapsed from the first contract. In line with the discussion in Sect. 6.2.1., it may influence an extension decision in an inverse-U shape. We also used research budgets and contract periods to control for the size of individual research contracts. Finally, we added the PIs' positions and their school/department categories.

\subsection{Results}

\subsubsection{Estimation of Quarterly Research Budgets (Analysis 1)}

Table 6.5 displays the results of OLS regression analysis. Although the estimation models exhibit a low fit, the result from Model 2 reveals that the time elapsed from the first contract has an inverse-U-shaped effect, peaking at 2.2 years ( $58 \%$ increase) and budgets decrease when these ties exceeded 4 years (Fig. 6.3). These results are consistent with $\mathrm{H} 1$ regarding contract renewals.

Analysis 1 also reveals that a curvilinear effect of contract periods. The result implies a research budget discount, resulting from the risks of uncertainty in performance-outcome effectiveness accompanying with a long-term contract. Interestingly, on average, PIs in the humanities and social sciences receive a larger budget per quarter than those in other fields. The result is influenced by several field

\footnotetext{
${ }^{1}$ Reported in the digital supplement are available at the authors' institutional repository: http://pubs. iir.hit-u.ac.jp/admin/en/pdfs/show/2478
} 
6 Determinants of Contract Renewals in University-Industry Contract. .

Table 6.5 Analysis 1: OLS regression results for quarterly research budgets

\begin{tabular}{|c|c|c|}
\hline & \multicolumn{2}{|c|}{ Ln (quarterly research budgets +1 ) } \\
\hline & Model 1 & Model 2 \\
\hline Time elapsed from the first contract & $0.055(0.071)$ & $0.410 * *(0.071)$ \\
\hline Time elapsed from the first contract (squared) & & $-0.092 * * *(0.008)$ \\
\hline Extension & $0.870(0.396)$ & $0.895(0.398)$ \\
\hline Initial contract periods (quarters) & $-0.118 * *(0.023)$ & $-0.116 * *(0.023)$ \\
\hline On-site industry researchers & $0.669^{* *}(0.172)$ & $0.676 * *(0.171)$ \\
\hline PIs' U-I linkages & $-0.007(0.011)$ & $-0.012(0.010)$ \\
\hline \multicolumn{3}{|l|}{ Position (baseline: Lecturer/assistant professor) } \\
\hline Professor & $0.855 *(0.299)$ & $0.849 *(0.296)$ \\
\hline Associate Professor & $0.568(0.280)$ & $0.558(0.285)$ \\
\hline \multicolumn{3}{|l|}{ Department (baseline: Humanities/social sciences) } \\
\hline Medical/Pharmaceutical & $-1.231 * * *(0.056)$ & $-1.214 * * *(0.057)$ \\
\hline Biology/Other Medical & $-1.766 * * *(0.113)$ & $-1.748 * * *(0.115)$ \\
\hline Science/Engineering & $-0.657 * * *(0.020)$ & $-0.642 * * *(0.022)$ \\
\hline Constant & $12.590 * * *(0.290)$ & $12.432 * * *(0.291)$ \\
\hline Year dummies & Yes & Yes \\
\hline Observations & 1562 & 1562 \\
\hline R-squared & 0.056 & 0.060 \\
\hline
\end{tabular}

$* * *: \mathrm{p}<0.001, * *: \mathrm{p}<0.01, *: \mathrm{p}<0.05$. Cluster robust standard errors in parentheses (clustered by PI's department)

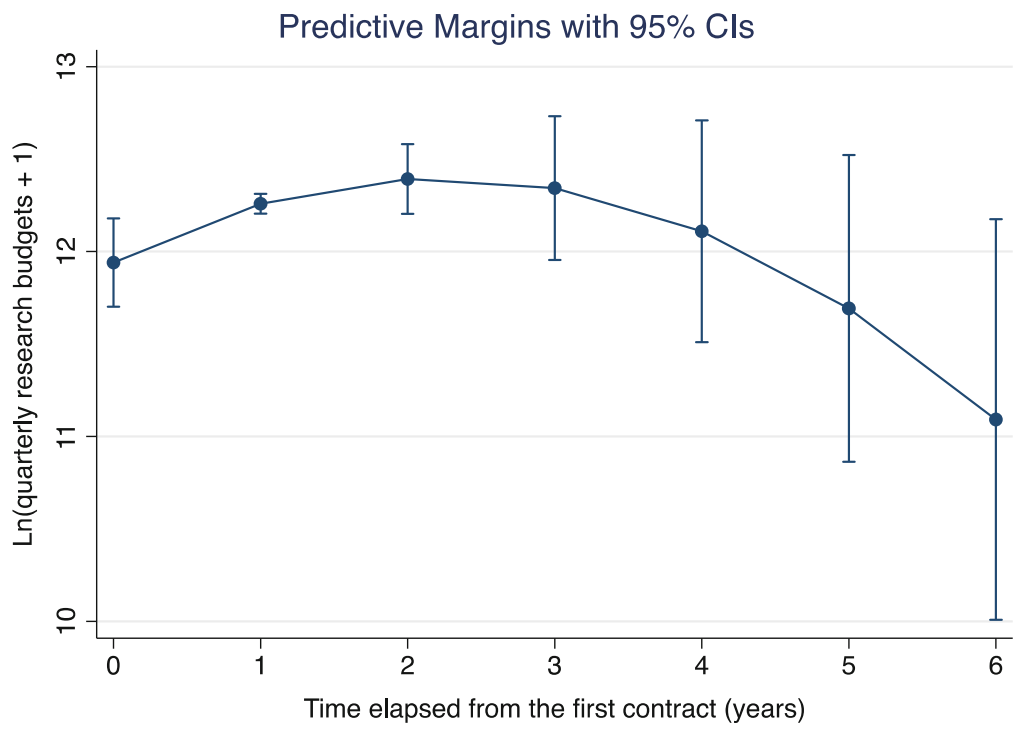

Fig. 6.3 Marginal effect of time elapsed from the first contract 
experiment projects in psychology and behavioural economics, which have shorter contract periods and larger budgets.

\subsubsection{Estimation of the Probability of Extension or Renewal (Analysis 2)}

Table 6.6 displays the results of logit regression analysis. Model 2 exhibits a significantly better fit than Model 1. The results indicate that satisfaction with outcomes shows a significant positive impact on extension or renewal. This finding is consistent with $\mathrm{H} 2$.

Table 6.6 Analysis 2: Logit regression results of the probability of extension or renewal

\begin{tabular}{|c|c|c|}
\hline & \multicolumn{2}{|c|}{ Subsequent renewal or extension dummy } \\
\hline & Model 1 & Model 2 \\
\hline Satisfaction with outcomes & $1.286 *(0.195)$ & $1.483 * *(0.293)$ \\
\hline \multicolumn{3}{|l|}{ Outcomes } \\
\hline Technological knowledge acquisition & & $2.412 * *(0.831)$ \\
\hline Patent application & & $0.569(0.275)$ \\
\hline Academic paper publication & & $4.600^{* * *}(2.398)$ \\
\hline Valuable data acquisition & & $1.006(0.419)$ \\
\hline Staff skill development & & $0.168^{* * *}(0.046)$ \\
\hline Creating social ties with faculty & & $3.219^{* * *}(1.273)$ \\
\hline New project establishment & & $0.987(0.670)$ \\
\hline Contribution to R\&D/NPD & & $0.207 * * *(0.032)$ \\
\hline Time elapsed from the first contract & $1.811(0.658)$ & $2.158 * * *(0.644)$ \\
\hline Time elapsed from the first contract (squared) & $0.932(0.068)$ & $0.877 * *(0.055)$ \\
\hline On-site industry researchers & $0.879(0.139)$ & $0.920(0.117)$ \\
\hline $\operatorname{Ln}($ research budgets +1$)$ & $1.335 * * *(0.110)$ & $1.390 * * *(0.036)$ \\
\hline Contract periods (quarters) & $1.065(0.066)$ & $1.108 * * *(0.039)$ \\
\hline PIs' U-I linkage & $1.020(0.045)$ & $1.073(0.068)$ \\
\hline \multicolumn{3}{|l|}{ Position (baseline: Lecturer/assistant professor) } \\
\hline Professor & $0.191(0.311)$ & $0.220(0.258)$ \\
\hline Associate Professor & $0.177(0.320)$ & $0.180(0.278)$ \\
\hline \multicolumn{3}{|l|}{ Department (baseline: Humanities/social sciences) } \\
\hline Medical/Pharmaceutical & $3.523 * * *(0.415)$ & $5.058 * * *(1.619)$ \\
\hline Biology/Other Medical & $3.508 * * *(0.225)$ & $4.435 * * *(1.052)$ \\
\hline Science/Engineering & $5.406 * * *(0.262)$ & $11.669 * * *(1.564)$ \\
\hline Constant & $0.008 *(0.021)$ & $0.001 * * *(0.001)$ \\
\hline Observations & 137 & 137 \\
\hline Pseudo R-squared & .109 & .202 \\
\hline
\end{tabular}

***: $\mathrm{p}<0.001, * *: \mathrm{p}<0.01, *: \mathrm{p}<0.05$. Odds ratio. Cluster robust standard errors in parentheses (clustered by PI's department) 
Some output-related outcome categories (see Perkmann et al., 2011) have a significant positive effect on the probability of subsequent contracts. Technology acquisition and academic paper publication increase this probability. The odds ratio for recognizing technological knowledge acquisition as an important outcome is 2.4. Contradicting our argument presented in the literature review, academic paper publication also increases the probability of renewal or extension, with the odds ratio for this outcome being 4.6, a higher value. Other explicit outputs, such as patents or valuable data, do not have statistically significant effects. Another output, staff skill development, significantly decreases the probability of the renewal or extension; its odds ratio is 0.17 .

Among impact-related outcomes, creating a social network with faculties increases the probability of extension or renewal. When firms recognize a contribution to their internal research and development, they are less likely to continue the collaboration. However, the establishment of a new project does not increase the probability of renewal or extension. Overall, a heterogeneity in outcomes has a different influence on renewal or extension decisions, which is consistent with $\mathrm{H} 3$.

Other than the independent variables, the time elapsed from the first contract has a curvilinear effect similar to Analysis 1. Its inverse-U-shaped effect hit the peak at the point of 2.9 years from the first contract.

\subsection{Discussion}

\subsubsection{The Gap Between Contract Periods and Ideal Length of Collaboration}

The results of Analysis 1 display the inverse-U-shaped effect of time elapsed from the start of a collaboration on the commitment, as theories predicted. Firms increase their commitment to the collaboration within the first 2-3 years. This estimated average ideal period of collaboration almost overlaps with Katz and Allen's (1982) findings, which identified the peak of the value of collaboration at around 2-4 years. Nevertheless, the majority $(76 \%)$ of contracts in our dataset expire within 1 year. These contracts indicate a higher probability of renewals and extensions $(63 \%)$ than longer-term contracts $(56 \%)\left(\chi^{2}=5.22, \mathrm{p}<0.05\right)$. This means that contract renewals and extensions are essential for firms to at least acquire the best return from contract research.

This gap between contract practice and an ideal interaction illustrates the value of contract management in relational-based interactions. As debated in our literature review section, a long-term interaction carries a trade-off between the pros of stable relationships (e.g., efficient communication and the formation of trust) and the cons of long-term formal commitment (e.g., uncertainty in performance-outcome effectiveness). To balance, firms implement a research management system, such as meetings among managers, informal contacts, technical reports, or research plan 
reviews (Morandi, 2013). Our study finds that contract management also constitutes an essential part of such a research management system in university-industry collaboration. We also reveal that the trade-off leads to a long-term commitment discount on the budget. A single long-term contract will involve a slightly lower budget, and its length linearly decreases the budget. We can assume that a PI and the industry-university liaison office discount research budgets to obtain stable funding and that firms reduce budgets in consideration of the risks of uncertainty.

We must note one limitation of the interpretation of our empirical results. Combined with our other finding that a long-term contract often discounts its research budgets, some may conclude that our results evidence the stage-gate system's superiority for university fundraising. Such an interpretation, however, neglects the probability of the termination of the research project. The subsequent collaboration contracts observed survive because of their prospects. It is natural for firms to allocate a higher budget to prospective collaborations. Our estimated model shows that even in the ideal case, in which a PI and his or her counterparts have already collaborated for 2 years, the probability of continuation remains around $75 \%$. An expected total volume of funds in a stage-gate system is not always larger than in a long-term contract. Our results only emphasize the importance of efforts to maintain collaborations for universities when they enter short-term or stage-gate research contracts.

\subsubsection{Determinants of a Long-Term Contract Research Project}

The empirical test in Analysis 2 illustrates how experiential learning is essential for firms to overcome unease regarding the prediction of performance-outcome effectiveness (Schwab \& Miner, 2008; Ebers \& Maurer, 2016). Innovation studies emphasize the importance of legitimizing an innovation project in a firm, as its uncertainty frequently generates internal pressures not to continue (Takeishi et al., 2010). Thus, once certain intermediate outcomes are perceived and deemed satisfactory, they will consider the maintenance of collaborative relationships legitimate.

In addition to the effect of overall satisfaction of outcomes, our results prove that the characteristics of outcomes strongly influence the decision to continue a collaboration. Among multiple outcomes expected in contract research (Perkmann et al., 2011), a perception of technological knowledge acquisition positively affects the maintenance of a collaboration. This result is in line with the literature emphasizing that many firms place a priority on continuous technology acquisition and learning from the university-industry connection (Cyert \& Goodman, 1997; McKelvey et al., 2015).

Other than the implicit perception of technological capability development, it is noteworthy that academic publications increase the probability of long-term formal relationships, whereas patents and data do not. These results are counterintuitive, as 
the industry generally prioritizes patents and data over publications. One may suspect that academic publications merely capture the scientific basis of contract research, which typically takes a long time. Publications may be considered a sign of the smooth progress of the project. This interpretation partly explains the result; however, it neglects firms' inherent opportunistic behaviour (Olk \& Young, 1997). Once firms acquire general knowledge, they can choose not to collaborate with the focal academic researcher in a formal contractual relationship. They can continue research internally, as published scientific knowledge is nonexclusive, or they can collaborate with other academic researchers with expertise in their applied fields. Our result seems to be a puzzle.

This puzzle can be understood from two theoretical perspectives. From the perspective of the formation of trust, these formal outputs are likely a proxy of mutual trust (Bruneel et al., 2010). Most publications are jointly authored. Writing academic papers creates reciprocal communication that facilitates and strengthens trust. In addition to that, successful publications increase the commitment of academic researchers to contract research (Lauvas \& Steinmo, 2021), as publication is important for academic scholars. This increased commitment may strengthen firms' expectation for further deliverables from the project. From an organizational decision perspective, the existence of explicit deliverables legitimatizes further spending for the research project. Publications are apparent "boundary-objects" (Koskinen, 2005 ) that link project members with their colleagues and managers and validate the progress of the project (Morandi, 2013).

Nevertheless, other explicit outputs, such as patents and valuable data, do not always increase the probability of contract continuation. A traditional R\&D management model can explain the difference (e.g., Balachandra \& Brockhoff, 1995). The model sets a typical decision point between development and manufacturing/ marketing launch. Although we cannot say that all these explicit outputs correspond to the transition in the R\&D process, we expect that many of them are signs of proceeding to the downstream phase. In such a phase, academic researchers often have little expertise. Firms do not have sufficient internal legitimization to maintain formal connections with academic researchers anymore. If so, patents and valuable data may have mixed effects on contract continuation. As fruits of mutual trust or boundary-objects, they increase the probability of the further formal collaboration, whereas they eliminate the legitimacy of maintaining the collaboration, as they indicate the appropriate timing of the termination of the collaboration. Therefore, they do not have any significant effects. Our interpretation is consistent with the estimation result of the effect of contribution to R\&D/NPD, as it is also regarded as a sign of the transition to the development phase.

The argument above emphasizes firms' constraints in resource allocation coming from rational organizational decisions. Both academic publications and technological capability development are almost dominant outputs from the academic sector, whereas other outputs and impact can be archived through collaboration with the non-academic sector. Firms may prioritize the unique value of academia as a part of rational decisions. The confirmed negative effect of staff skill development seems to 
share the same theoretical ground. Continuing the allocation of already-developed $\mathrm{R} \& \mathrm{D}$ personnel in contract research is irrational behaviour.

Nevertheless, perceived social ties with PIs are correlated positively with the contract renewal or extension decision. We can interpret this as a consequence of a sense of reciprocity, which is heightened through social exchange relationships (Gouldner, 1960). Firms seem to believe that opportunistic behaviour, which concludes contract research and maintains a social network with the focal PI via informal channels, will decrease the accessibility of academic knowledge. They may recognize the importance of reciprocity and mutual trust in technological learning (Mody, 1993). In this sense, it also constitutes rational decisions.

\subsection{Conclusion}

This paper investigated longitudinal changes in the commitment to collaborative university-industry research and the determinants of contract renewals. We focused on industry firms' decision to renew or extend an existing research contract to reveal the effects of project-related factors. Our empirical analyses find that the strength of the commitment to the renewed contract follows an inverse-U-shaped relationship in the time elapsed from the first contract. We also demonstrated that the perceived development of technological capability and academic paper publication lead to a further formal collaboration with the counterparts. Concurrently, our results imply that firms are likely to terminate the relationship when there is no longer a rational business reason to continue the formal collaboration with the academic researcher. This finding sets a limitation to the argument by Ankrah et al. (2013), who emphasizes that firms have fundamental motives to maintain long-term connections. Although this argument is partly true, firms also seek a unique value from university-industry collaboration.

Our findings suggest that concentrating on academic publications and knowledge-sharing with industry collaborators is, in general, likely to establish long-term university-industry connections. It is noteworthy that these activities are fundamental university roles. Some claim the need for academic scholars to be good partners of industry (or "good Sams"), but data show the opposite need. Based on our research findings, academic scholars are encouraged to be "going my way," even in university-industry collaborations.

This paper's main academic contribution lies in its discovery of the importance of contract renewals in the context of university-industry relational arrangements. As De Wit-de Vries et al. (2019) find, most papers have focused on the informal management aspects of university-industry research partnerships, and limited studies have been conducted on the formal management of such collaborative efforts. Our paper confirms the value of a long-neglected perspective for future research.

One essential practical contribution of this study is the confirmation of concrete determinants of long-term university-industry collaborations. Establishing an open atmosphere in academic publishing is beneficial for both academia and industry. 
However, as Battilana et al. (2009) noted, firms sometimes emphasize the secrecy of research outputs, placing some constraints on the academic publication of academic counterparts. Such constraints seem to be reasonable acts of risk aversion, but our findings imply that these constraints may lack foresight for firms. In order to avert these adverse conditions, technology transfer offices, research administrators, and industry liaison offices play an important role in negotiating research contracts (e.g., Berbegal-Mirabent et al., 2015).

As with most empirical research, this study has some limitations. First, the empirical analysis still has several unobserved variable biases, although we constructed a rich dataset based on highly reliable trajectories of research contracts matched with multiple data sources. Typically, we would neglect the PIs' scholarly productivity because of data availability; instead, we inserted PIs' university-industry connections as a control variable. This variable primarily proxies for the weakness of commitment, but the indicator simultaneously reflects the focal point of PIs' attractiveness, which might correspond to academic productivity (e.g., Gulbrandsen \& Smeby, 2005). Second, the majority of our samples are contracts between Japanese firms and the Japanese research university from which the data were derived, while contract practices likely differ among countries. Further validations are necessary to generalize our findings. Finally, our subset of samples in Analysis 2 is not completely balanced with the full samples of Analysis 1, meaning that the results of Analysis 2 are potentially biased.

A long-term relationship is beneficial, but has limitations. Short-term contracts are sometimes the result of inevitable choice. Our findings provide one significant implication, in that going academic way is a key to collaborate with the industry in the long term.

\section{References}

Al-Tabbaa, O., \& Ankrah, S. (2016). Social capital to facilitate 'engineered' university-industry collaboration for technology transfer: A dynamic perspective. Technological Forecasting and Social Change, 104, 1-15.

Ankrah, S. N., Burgess, T. F., Grimshaw, P., \& Shaw, N. E. (2013). Asking both university and industry actors about their engagement in knowledge transfer: What single-group studies of motives omit. Technovation, 33(2-3), 50-65.

Arza, V., \& Carattoli, M. (2017). Personal ties in university-industry linkages: A case-study from Argentina. The Journal of Technology Transfer, 42(4), 814-840.

Balachandra, R., \& Brockhoff, K. (1995). Are R\&D project termination factors universal? Research-Technology Management, 38(4), 31-36.

Banal-Estañol, A., Jofre-Bonet, M., \& Lawson, C. (2015). The double-edged sword of industry collaboration: Evidence from engineering academics in the UK. Research Policy, 44(6), $1160-1175$

Battilana, J., Leca, B., \& Boxenbaum, E. (2009). How actors change institutions: Towards a theory of institutional entrepreneurship. Academy of Management Annals, 3(1), 65-107.

Berbegal-Mirabent, J., García, J. L. S., \& Ribeiro-Soriano, D. E. (2015). University-industry partnerships for the provision of R\&D services. Journal of Business Research, 68(7), $1407-1413$. 
Bishop, K., D'Este, P., \& Neely, A. (2011). Gaining from interactions with universities: Multiple methods for nurturing absorptive capacity. Research Policy, 40(1), 30-40.

Bodas Freitas, I. M., Geuna, A., \& Rossi, F. (2013). Finding the right partners: Institutional and personal modes of governance of university-industry interactions. Research Policy, 42(1), $50-62$.

Bruneel, J., D'Este, P., \& Salter, A. (2010). Investigating the factors that diminish the barriers to university-industry collaboration. Research Policy, 39(7), 858-868.

Bstieler, L., Hemmert, M., \& Barczak, G. (2015). Trust formation in university-industry collaborations in the US biotechnology industry: IP policies, shared governance, and champions. Journal of Product Innovation Management, 32(1), 111-121.

Cyert, R. M., \& Goodman, P. S. (1997). Creating effective university-industry alliances: An organizational learning perspective. Organizational Dynamics, 25(4), 45-58.

De Fuentes, C., \& Dutrénit, G. (2012). Best channels of academia-industry interaction for longterm benefit. Research Policy, 41(9), 1666-1682.

D'Este, P., \& Perkmann, M. (2011). Why do academics engage with industry? The entrepreneurial university and individual motivations. The Journal of Technology Transfer, 36(3), 316-339.

D'Este, P., Llopis, O., Rentocchini, F., \& Yegros, A. (2019). The relationship between interdisciplinarity and distinct modes of university-industry interaction. Research Policy, 48(9), 103799.

De Wit-de Vries, E., Dolfsma, W. A., van der Windt, H. J., \& Gerkema, M. P. (2019). Knowledge transfer in university-industry research partnerships: A review. The Journal of Technology Transfer, 44(4), 1236-1255.

Dingler, A., \& Enkel, E. (2016). Socialization and innovation: Insights from collaboration across industry boundaries. Technological Forecasting and Social Change, 109, 50-60.

Ebers, M., \& Maurer, I. (2016). To continue or not to continue? Drivers of recurrent partnering in temporary organizations. Organization Studies, 37(12), 1861-1895.

Frasquet, M., Calderón, H., \& Cervera, A. (2012). University-industry collaboration from a relationship marketing perspective: An empirical analysis in a Spanish University. Higher Education, 64(1), 85-98.

Galan-Muros, V., \& Plewa, C. (2016). What drives and inhibits university-business cooperation in Europe? A comprehensive assessment. $R \& D$ Management, 46(2), 369-382.

Garcia, R., Araújo, V., Mascarini, S., Santos, E. G., \& Costa, A. R. (2020). How long-term university-industry collaboration shapes the academic productivity of research groups. Innovations, 22(1), 56-70.

Garcia, R., Araújo, V., Mascarini, S., Santos, E. G., \& Costa, A. R. (2019). How the benefits, results and barriers of collaboration affect university engagement with industry. Science and Public Policy, 46(3), 347-357.

Gouldner, A. W. (1960). The norm of reciprocity. American Journal of Sociology, 25, 161-178.

Gulbrandsen, M., \& Smeby, J. C. (2005). Industry funding and university professors' research performance. Research Policy, 34(6), 932-950.

Hagedoorn, J., Link, A. N., \& Vonortas, N. S. (2000). Research partnerships. Research Policy, 29(4-5), 567-586.

Hamel, G. (1991). Competition for competence and interpartner learning within international strategic alliances. Strategic Management Journal, 12(S1), 83-103.

Im, G., \& Rai, A. (2008). Knowledge sharing ambidexterity in long-term interorganizational relationships. Management Science, 54(7), 1281-1296.

Jelinek, M., \& Markham, S. (2007). Industry-university IP relations: Integrating perspectives and policy solutions. IEEE Transactions on Engineering Management, 54(2), 257-267.

Katz, R., \& Allen, T. J. (1982). Investigating the not invented here (NIH) syndrome: A look at performance, tenure, and communication pattern of $50 \mathrm{R} \& \mathrm{D}$ project groups. $R \& D$ Management, 12(1), 7-19.

Kameo, N. (2015). Gifts, donations, and loose coupling: Responses to changes in academic entrepreneurship among bioscientists in Japan. Theory and Society, 44(2), 177-198. 
Koskinen, K. U. (2005). Metaphoric boundary objects as co-ordinating mechanisms in the knowledge sharing of innovation processes. European Journal of Innovation Management, 8(3), 323-335.

Koza, M. P., \& Lewin, A. Y. (1998). The co-evolution of strategic alliances. Organization Science, 9(3), 255-264.

Landry, R., Saïhi, M., Amara, N., \& Ouimet, M. (2010). Evidence on how academics manage their portfolio of knowledge transfer activities. Research Policy, 39(10), 1387-1403.

Lauvas, T., \& Steinmo, M. (2019). The role of proximity dimensions and mutual commitment in shaping the performance of university-industry research centres. Innovations, 23(2), 1-27.

Lee, Y. S. (2000). The sustainability of university-industry research collaboration: An empirical assessment. The Journal of Technology Transfer, 25(2), 111-133.

McKelvey, M., Zaring, O., \& Ljungberg, D. (2015). Creating innovative opportunities through research collaboration: An evolutionary framework and empirical illustration in engineering. Technovation, 39-40, 26-36.

Mody, A. (1993). Learning through alliances. Journal of Economic Behavior and Organization, 20(2), 151-170.

Morandi, V. (2013). The management of industry-university joint research projects: How do partners coordinate and control R\&D activities? The Journal of Technology Transfer, 38(2), 69-92.

Motoyama, Y. (2014). Long-term collaboration between university and industry: A case study of nanotechnology development in Japan. Technology in Society, 36, 39-51.

Olk, P., \& Young, C. (1997). Why members stay in or leave an R\&D consortium: Performance and conditions of membership as determinants of continuity. Strategic Management Journal, 18(11), 855-877.

Perkmann, M., \& Walsh, K. (2007). University-industry relationships and open innovation: Towards a research agenda. International Journal of Management Reviews, 9(4), 259-280.

Perkmann, M., King, Z., \& Pavelin, S. (2011). Engaging excellence? Effects of faculty quality on university engagement with industry. Research Policy, 40(4), 539-552.

Petruzzelli, A. M. (2011). The impact of technological relatedness, prior ties, and geographical distance on university-industry collaborations: A joint-patent analysis. Technovation, 31(7), 309-319.

Plewa, C., \& Quester, P. (2006). Satisfaction with university-industry relationships: The impact of commitment, trust and championship. International Journal of Technology Transfer and Commercialisation, 5(1-2), 79-101.

Plewa, C., Korff, N., Baaken, T., \& Macpherson, G. (2013). University-industry linkage evolution: An empirical investigation of relational success factors. $R \& D$ Management, 43(4), 365-380.

Santoro, M. D., \& Saparito, P. A. (2006). Self-interest assumption and relational trust in universityindustry knowledge transfers. IEEE Transactions on Engineering Management, 53(3), 335-347.

Schildt, H., Keil, T., \& Maula, M. (2012). The temporal effects of relative and firm-level absorptive capacity on interorganizational learning. Strategic Management Journal, 33(10), 1154-1173.

Schwab, A., \& Miner, A. S. (2008). Learning in hybrid-project systems: The effects of project performance on repeated collaboration. Academy of Management Journal, 51(6), 1117-1149.

Starbuck, E. (2001). Optimizing university research collaborations. Research-Technology Management, 44(1), 40-44.

Steinmo, M., \& Rasmussen, E. (2018). The interplay of cognitive and relational social capital dimensions in university-industry collaboration: Overcoming the experience barrier. Research Policy, 47(10), 1964-1974.

Swanson, R. A. (2001). Human resource development and its underlying theory. Human Resource Development International, 4(3), 299-312.

Takeishi, A., Aoshima, Y., \& Karube, M. (2010). Reasons for innovation: Legitimizing resource mobilization for innovation in the cases of the Okochi Memorial Prize Winners. In H. Itami, 
K. Kusunoki, T. Numagami, \& A. Takeishi (Eds.), Dynamics of knowledge, corporate systems and innovation (pp. 165-189). Springer Berlin Heidelberg.

Thomas, Lauvås Marianne, Steinmo (2021) The role of proximity dimensions and mutual commitment in shaping the performance of university-industry research centres. Innovation 23(2) 182-208. https://doi.org/10.1080/14479338.2019.1662725

Tijssen, R. J., Van Leeuwen, T. N., \& Van Wijk, E. (2009). Benchmarking university-industry research cooperation worldwide: Performance measurements and indicators based on co-authorship data for the world's largest universities. Research Evaluation, 18(1), 13-24.

Vohora, A., Wright, M., \& Lockett, A. (2004). Critical junctures in the development of university high-tech spinout companies. Research Policy, 33(1), 147-175.

Wang, C., Schmidt, G., \& van der Rhee, B. (2018). Stage-gate contracts to screen agents with inside information. Decision Sciences, 49(6), 1156-1186.

Weckowska, D. M. (2015). Learning in university technology transfer offices: Transactionsfocused and relations-focused approaches to commercialization of academic research. Technovation, 41, 62-74.

Yegros-Yegros, A., Azagra-Caro, J. M., López-Ferrer, M., \& Tijssen, R. J. (2016). Do universityindustry co-publication outputs correspond with university funding from firms? Research Evaluation, 25(2), 136-150.

Zheng, Y., \& Yang, H. (2015). Does familiarity foster innovation? The impact of alliance partner repeatedness on breakthrough innovations. Journal of Management Studies, 52(2), 213-230.

Open Access This chapter is licensed under the terms of the Creative Commons Attribution 4.0 International License (http://creativecommons.org/licenses/by/4.0/), which permits use, sharing, adaptation, distribution and reproduction in any medium or format, as long as you give appropriate credit to the original author(s) and the source, provide a link to the Creative Commons license and indicate if changes were made.

The images or other third party material in this chapter are included in the chapter's Creative Commons license, unless indicated otherwise in a credit line to the material. If material is not included in the chapter's Creative Commons license and your intended use is not permitted by statutory regulation or exceeds the permitted use, you will need to obtain permission directly from the copyright holder.

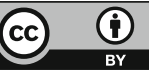

